\title{
Prospective mathematics teachers' argumentation structure when constructing a mathematical proof: The importance of backing
}

\author{
Christina M. Laamena ${ }^{1}$, Toto Nusantara ${ }^{2}$
}

\begin{abstract}
Abstrak: Penelitian kualitatif dengan desain fenomenologi ini bertujuan untuk menyelidiki penggunaan backing dan hubungannya dengan rebuttal dan qualifier dalam membangun bukti matematika terkait fungsi aljabar oleh calon guru matematika. Data dikumpulkan melalui hasil kerja siswa, rekaman think aloud, dan wawancara mendalam. Analisis data merujuk pada skema argumentasi Toulmin. Hasil penelitian menunjukkan bahwa backing yang digunakan siswa tidak hanya berbentuk teorema atau definisis (reference backing) tetapi juga contoh-contoh bilangan (numerical backing) dan grafik fungsi (graphical backing). Ketiga jenis backing tersebut untuk memperkuat warrant induktif maupun deduktif. Numerical backing digunakan ketika warrant tidak dapat menjustifikasi kebenaran klaim. Graphical backing digunakan untuk meyakinkan diri sendiri tentang kebenaran klaim yang telah dibuat sedangkan reference backing hanya bersifat klarifikasi karena siswa telah memahami pernyataan yang diberikan. Numerical backing dan graphical backing berhubungan langsung dengan rebuttal untuk memberikan contoh penyangkal dan jaminan kebenaran (qualifier) klaim. Numerical backing membuat siswa lebih percaya diri tentang klaim yang dihasilkan dibandingkan dengan reference backing.
\end{abstract}

Kata kunci : Argumentasi, Bukti matematis, Backing

\begin{abstract}
This qualitative study with phenomenology design aims to investigate the use of backing and its relation to rebuttal and qualifier in prospective mathematics teachers' (PMTs) argumentation when constructing a mathematical proof about algebraic function. The data were collected through subjects' works on the proof, recorded think-aloud data, and in-depth interviews. Data analysis was guided by Toulmin's argumentation scheme. The results show that the PMTs used three types of backing, i.e., backing in the form of definitions or theorems (reference backing), examples of numbers (numerical backing) and graphs of functions (graphical backing). The PMTs utilized the backings to strengthen deductive and inductive warrant. A numerical backing is used when a warrant cannot justify the truth of a claim. Graphical backing is used to convince oneself about the truth of the data that has been made while the reference backing is only clarification when students have understood or have knowledge of the statement given. Numerical and graphical backing relate directly to rebuttal and provide counter-examples and qualifier of the claim. A numerical backing makes students more confident about claims that are generated compared to reference backing.
\end{abstract}

Keywords: Argumentation, Mathematical proof, Backing

\section{A. Introduction}

In mathematics, proofs have a very important role, and thus they are a key area of mathematics education research (Bar-Tikva \& Judith, 2009). Formulating a proof and proving

\footnotetext{
${ }^{1}$ Universitas Pattimura, Jln. Ir. M. Putuhena, Ambon, Indonesia, christinmath18@gmail.com

${ }^{2}$ Universitas Negeri Malang, Jln. Semarang No. 5, Malang, Indonesia
} 
is crucial for doing, understanding and communicating mathematical knowledge (Stylianides, 2007), which is why the proof has gained increasing attention in recent years (Stylianides, 2007; Hanna \& Villiers, 2012). Various researches on the process of constructing proofs have been carried out (Selden, Selden \& Benkhalti, 2018; Inglis \& Mejia-ramos, 2009; Stylianides \& Stylianides, 2009). The results of the studies indicate that in constructing a mathematical proof, one does not always follow deductive rules, but also inductive aspects such as empirical proof, special cases or graphs (Tymoczko, 1986; Arzarello, 2007; Feferman, 2000; Mejía-Ramos \& Inglis, 2008; Burton, 2004). Those inductive aspects are used to understand propositions to be proved and to find relationships between propositions (Arzarello, Paola \& Sabena, 2009). Arguments will occur during the process of constructing a proof to support some of the justifications (arguments) that have been produced (Boero, Garuti, \& Mariotti, 1996) and to produce a valid conclusion.

Toulmin's argumentation scheme has been used by many mathematical education researchers to analyze the process of formulating proofs (Knipping, 2008; Pedemonte, 2007; Mejía-Ramos \& Inglis, 2008), constructing definitions (Ubuz, Dincer, \& Bülbül, 2013) and solving mathematical problems (Ubuz, Dincer, \& Bülbül, 2012; Solar \& Deulofeu, 2016) because it covers the use of informal argumentation. Including informal argumentation is important since sometimes students use graphics or examples to prove a mathematical conjecture. Toulmin's argumentation scheme (Figure 1) consists of three main components, namely data, claims, and warrant and three complementary components, i.e., backing, rebuttal, and modal qualifier.

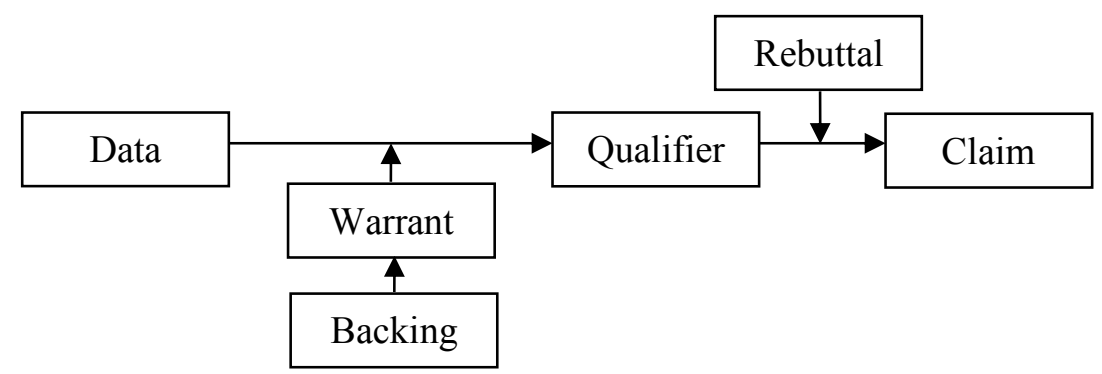

Figure 1. Toulmin's argumentation scheme

According to Toulmin (2003), Data (D) is the foundation of the argument. It consists of facts that support the claim. Claim (C) is a statement or conclusion made based on data. Warrant $(\mathrm{W})$ is like a bridge that links data and claim and becomes the basis of the thought or reason used to generate conclusions. A warrant may take the form of formulas, definitions, axioms or theorems, or it may consist of inductive aspects, like drawings, diagrams, and graphs. A warrant is reinforced by backing (B), which is further evidence or additional reasons needed. Rebuttal $(\mathrm{R})$ is a statement that denies the resulting conclusion if the condition is not fulfilled (Toulmin, 2003, p. 132).

The Toulmin scheme has not to be used in the exact way it was initially proposed: It can flexibly be re-structured or focused in various ways (Hitchcock \& Verheij, 2006). Many mathematical education researchers applied the Toulmin model by adapting it to their needs. Krummheuer (1995) and Pedemonte $(2003,2007)$ reduced backing, rebuttal and modal qualifier. Knipping (2013), Ubuz, et al., (2012, 2013), Pedemonte, (2007) and Chen and Wang (2016) reduced rebuttal and modal qualifier. A typical reason for doing so is that the backing component 
is assumed to be a theorem or a definition (Inglis, Mejia-Ramos, \& Simpson, 2007). The current study focused on the backing component and its relation qualifier and rebuttals.

A warrant can be supported or reinforced in different ways (Toulmin, 2003). For example, 'A whale will be (i.e., is classifiable as) a mammal', 'A Bermudan will be (in the eyes of the law) a Briton,' 'A Saudi Arabian will be (found to be) a Muslim.' The words in brackets indicate the difference. The first warrant is supported by a natural classification that has been accepted, the second warrant is supported by law or rule, and the third warrant is supported by the presentation. Backing for warrants can be expressed in the form of definite statements, directly supporting the conclusions. The types of backing depend on the field of argument. In the three given examples, it was a juristical, biological, and demographical type of backing. Thus, the backing of warrants can be based on statistical reports, experimental results, or references.

Pedemonte (2003) argues that backing is required if a warrant is not accepted straight away. It means that a warrant cannot justify the claim. Chen and Wang (2016) explain that the validity of the argument depends significantly on the backing (whether an argument was valid or not). In this case, backing as one of the components in the Toulmin scheme plays a vital role in determining the truth of claims. Despite backing is crucial, we argue that it is still under-researched since limited prior research focused on the case (e.g., Ubuz et al., 2012; Simpson, 2015). Some researchers (Inglis, Mejia-Ramos, \& Simpson, 2007; Chen \& Wang, 2016) consider backing as a definition or theorem. Simpson (2015) highlighted three types of backings which relate to warrant, i.e., backing for the warrant's validity, backing for the warrant's field, and backing for the warrant's correctness. Ubuz et al., (2012) analyzed collective argumentation constructed by students and teachers in learning. In this case, the backing is from teachers not from students. It is named as guide-backing, which comprises three categories, i.e., approval, reference, and terminator. Approval guide backing is a approve from teacher to the students' warrant by saying for example "good, well done". When teacher approves the students' warrant, backing or claim by referring a definition, a theorem or a problem recently solved, they called as reference guide backing. If argumentation comes to an end when teacher or students reach the final claim to be achieved, then they called it as terminator guide backing. However, if argumentation occurs individually to solve one problem or proving a mathematical statement, the backing that comes from students becomes very important.

The current research pursued the investigation of the backings as a small number of prior researches did (e.g., Ubuz, et al., 2012; Simpson, 2015). However, it differs from the types of backing and their relation to rebuttal and qualifier in mathematical proof. We focused on a backing which applies for a valid warrant. Meanwhile, Simpson (2015) did for both valid and invalid warrant. We also investigated backing from students, not the teachers as Ubuz, et al., (2012) did in their research. In this paper, we want to answer the following questions which refer to the findings of our research: Is the backing used by PMTs always a theorem or a definition? Do they use only one type of backing to reinforce warrants in generating claims? What is the relationship of backing to rebuttal and qualifier in the proving? The answers to the questions are expected to contribute to the gaps of research concerning backing in a mathematical proof.

\section{B. Methods}

The study follows a qualitative research method: A phenomenology design is used to explain the phenomena that appeared in the argumentation structure of PMTs, i.e., specific types of backings used when constructing a proof and its relation to rebuttal and qualifier. Following the phenomenology design, data was collected through subjects' works on the proof, recorded 
think-aloud, and in-depth interview. The in-depth interview aims to analyze, identify, understand, and explain the students' thinking processes underlying each of their reactions and perceptions (Fraenkel, Wallen, \& Hyun, 2012) when working on the proof. We argue that this design is considered appropriate to characterize the types of backing that are generally used by students and their relationship with a rebuttal and modal qualifier.

For analyzing the argumentation structures, an algebraic problem was given to the subjects: A wrong mathematical statement was given and the students were expected to be able to determine counter-examples (rebuttals according to the Toulmin scheme). The problem was designed to show the components of argumentation (data, warrant, backing, claim, and rebuttal) and allows various ways of completion by using various forms of warrant and backing. Prior to use in research, the problem has been validated by experts. The tasks were given as follows:

\section{Suppose the function $f: \mathbb{R} \rightarrow \mathbb{R}$ by the formula $f(x)=x^{2}$ dan $g: \mathbb{R} \rightarrow \mathbb{R}$ by the formula $g(x)=x$. Investigate whether $f(x) \geq g(x)$ for all $x$ real numbers?}

The data collection began with providing the proving problem to forty-four (42) PMTs for individual completion. During their problem-solving process, they were asked to voice what they thought (think-aloud method). They were allowed to explore, write, and state all their thoughts and ideas without being limited by time. They should finish when they felt that they were not able to finish it or had no further ideas. When they worked on the problem, we observed and recorded all behaviors, including verbalized thoughts (according to the think-aloud method; the think-aloud-data was recorded via camera and then transcribed for further analysis). The subjects were then interviewed individually to explain their process of thinking when constructing the proof. For the interview procedure, a semi-structured clinical interview form was used (Ginsburg, 1981), i.e., we asked the participants to share what is on their mind as well as asking for further explanations of unclear answers or writings. During the interview, the subjects were given the opportunity to improve their answers without the intervention of the researchers. PMTs who answered correctly and used a backing were selected as research subjects. The selection of the subjects was done until the data collected has been saturated. Of the 42 participants, 23 students answered the problem correctly, and 19 students answered incorrectly. Six of twelve students who used backing were chosen for analysis.

We then analyzed all data (subjects' works on the proof, interviews, video graphed think-aloud data) and narrowed them through a sequencing process to the research-question-relevant parts. The analysis of the data was according to a multi-case-study approach by subsequently categorizing the narrowed data (Bromley, 1986). For this purpose, we classified the answers of students in three categories and discussed them with fellow researchers. The further determination of the categories was based on the framework of definitions that have been made. All research data were interpreted on the basis of indicators of Toulmin's argumentation model and its components, after which a complete argumentation structure to explain students' thinking processes was described.

\section{Findings and Discussion}

In this part, we will provide; the subjects' works on the proving problem which used backing along with some supporting excerpts of transcript, findings which drawn from the subjects' works and a discussion on the findings. The subjects' answers on the given problem were categorized into three as follows: 


\section{The subjects reinforce warrant with some numbers}

This first type of answer was done by $\mathrm{S} 1$ and $\mathrm{S} 2$ by clustering the real numbers into some groups of numbers. S1 expressed the real number as $\frac{a}{b}$ where $b \neq 0$, then grouped it referring to $a$ and $b$ : (1) $a, b \in \mathbb{Z}^{+}$where $a>b$ and $a<b$; (2) $a, b \in \mathbb{Z}^{-}$where $a>b$ and $a<b$. S1 proceeded to use sample of numbers $(a=-1, b=-2)$ and yielded the claim (Figure 2).

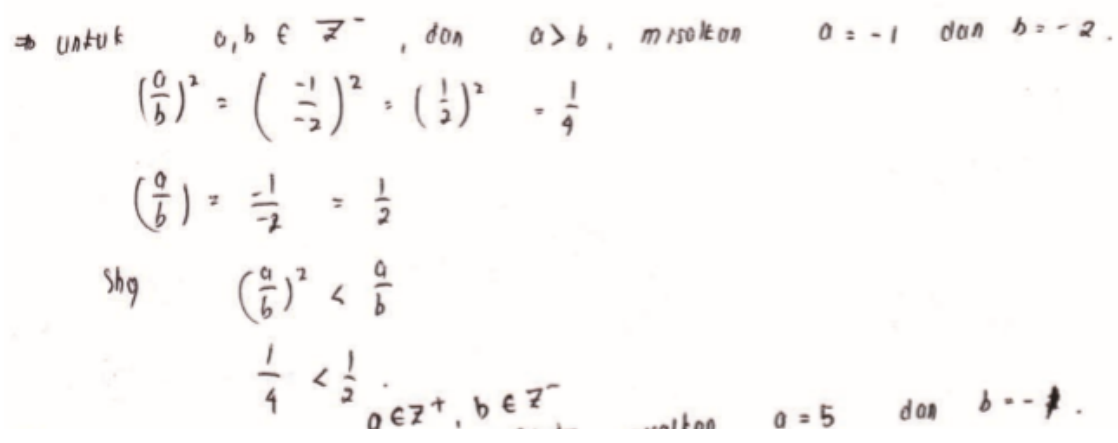

Figure 2. A sample of S1's work

The excerpt of the interview below reveals the thinking process of S1 and his reason for using the sample of numbers.

$R$ : How do you get the statement if $a<b$ then $f(x)<g(x)$ ?

S1: If $x=\frac{a}{b}$ then $x^{2}=\frac{a^{2}}{b^{2}}$ (pause) ... for $a<b$ then $\frac{a}{b}<\frac{a^{2}}{b^{2}}$ be $f(x)<g(x)$

$R$ : How do you get $a<b$ then $\frac{a}{b}<\frac{a^{2}}{b^{2}}$ ?

S1:From here mom (pointing to her work). Because if I take $a=-1$ and $b=-2$ then $\frac{1}{2}>\frac{1}{4}$

$R:$ Why do you take $a=-1$ and $b=-2$ ?

S1: Because I want to decide which one is greater, $\frac{a}{b}$ or $\frac{a^{2}}{b^{2}}$

$R$ : Is it not enough to decide with $a$ and $b$ only?

S1: If with $a$ and $b$, it's hard mom, I cannot solve.. I make it so.

(The excerpt of interview 1, EoI-1)

S2 grouped real numbers into positive numbers, null, negative numbers and fractions (Figure 3). S2 used samples of the numbers to produce the claims. The interview below shows that S2's claim was based on samples of the numbers from the grouped numbers.

S2: For $x$ is greater than null, I have $x^{2} \geq x$

$R$ : How? This (pointing to $S 2$ 's work $x>0$ yielded $x^{2} \geq x$ ), what is it? Please, explain slowly

S2: If $x$ is positive then $x^{2}$ must be positive. So, I have $x^{2} \geq x$

$R$ : Is it right? If $x$ is positive then exactly $x^{2} \geq x$ is positive

S2: Sure, because if I take $x=2, x^{2}=4$, it is $4>2$. So, $x^{2}>x$. Take $x=1$ where $x>0.1^{2}=1$ provides $x=x^{2}$ 


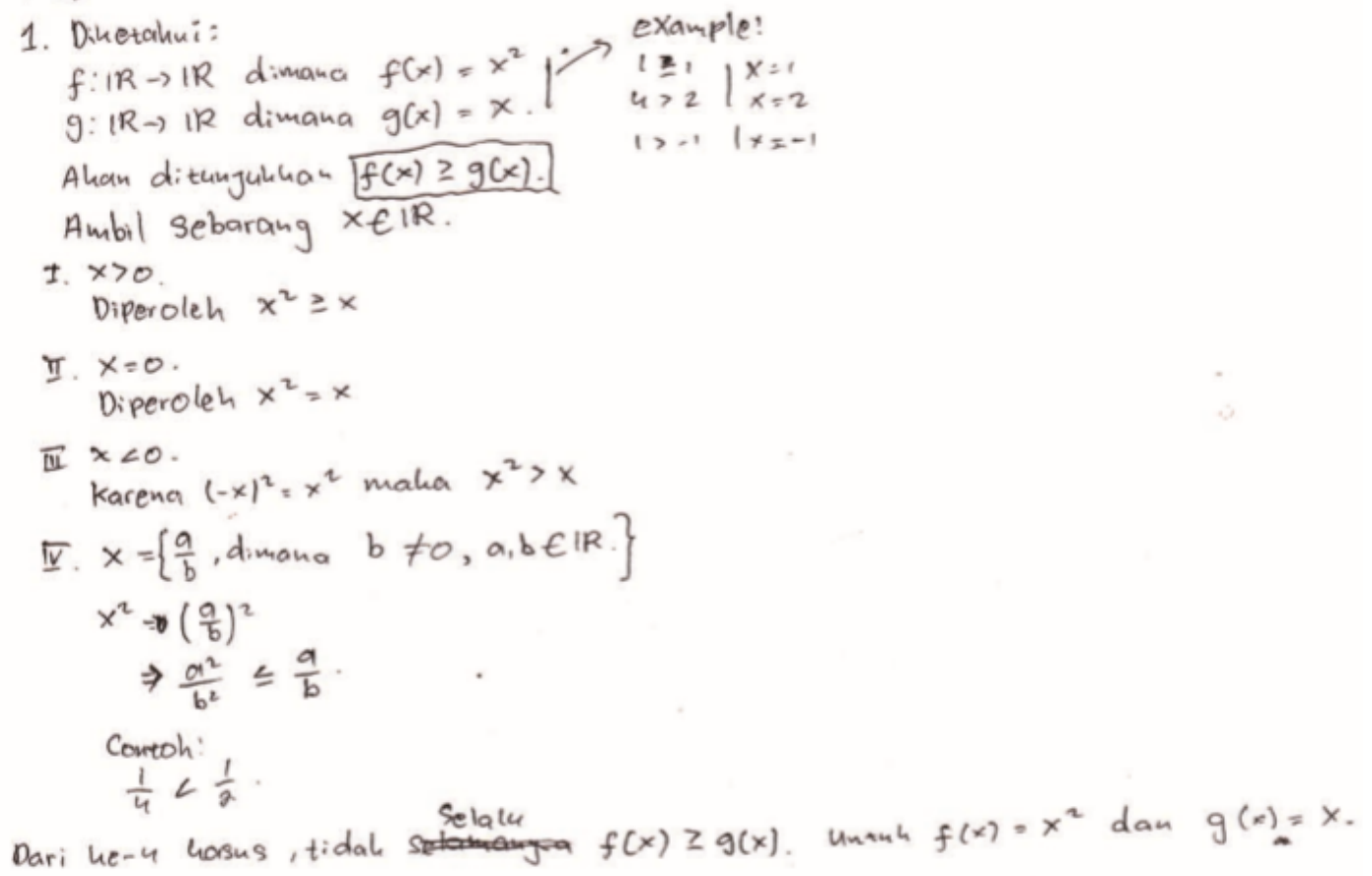

Figure 3. A sample of S2's work

\section{The subjects reinforce warrant with definition, theorem or the properties of numbers}

$\mathrm{S} 3$ and $\mathrm{S} 4$ did not use a sample of the numbers at all, but they used the properties of numbers. Figure $4 \mathrm{a}$ and Figure $4 \mathrm{~b}$ shows their works.

$$
\begin{aligned}
& \text { Misalkan ambi| } x=\frac{1}{a} \text { sedemikian sehing } \forall a \in z \\
& f(x) \geqslant g(x) \\
& \left(\frac{1}{a}\right)^{2} \geqslant \frac{1}{a} \text { of } \\
& \frac{1}{a^{2}} \geqslant \frac{1}{a} \\
& \text { karena } a^{2} \geqslant a \quad \forall a \in z \\
& \text { maka } \frac{1}{a^{2}}<\frac{1}{a} \quad r e \mid f(x)<g(x) .
\end{aligned}
$$

Figure 4a. A sample of S3's work

$$
\begin{aligned}
& \text { Ambic } \underset{x}{x} \in A \text {, dimana } A \subset \mathbb{R}, A=\{x \mid 0<x<1\} \\
& \text { dipilih } x=1 / 2 \\
& \text { Maka: } \quad f(x)=f(1 / 2):(1 / 2)^{2}=1 / 9 \\
& g(x)=g(1 / 2)=1 / 2 \\
& \text { Karena, } f(x)=1 / 4<1 / 2=g(x) \text {, maka tidak Semoa } x \in \mathbb{R} \\
& \text { yg Memeriuti } f(x) \geq g(x)
\end{aligned}
$$

Figure 4b. A sample of S4's work 
S3 had $x=\frac{1}{a}$ as counter-example. S4 had a short and correct answer but the interview shows that she used the properties of numbers before coming to $A=\{x \mid 0<x<1\}$ as counterexample. S4 used the property "the square of negative integers or positive integers remains positive" so $x^{2}>x$.

\section{The subjects reinforce warrant with a graph of function and numbers line}

In this category, there are two forms of answers (Figure 5a and 5b). S5 drew the graphs of $y=x^{2}$ and $y=x$ in a cartesian coordinate. S6 had produced the claim that $x^{2} \geq x$ but he achieved a different result in proof.

Referring to all subjects' works, as shown in Figure 2 to Figure $5 \mathrm{~b}$ and the excerpts of interviews, we found that the backing the students used was not always in the form of definitions or theorems. The subjects also used other backings such as examples of numbers, calculations, and graphs to help themselves produce claims. Both types (examples of numbers and graphs) of backing are used since students cannot make decisions based on a deductive or inductive warrant.

It is also found that three types of backing were used by the subjects namely numerical backing, graphical backing and reference backing. The terms numerical backing and graphical backing refer to the terms used by Arzarello et al., (2009) on numerical registers and graphical registers, while reference backing refers to Toulmin's (2003) references to indicate that the backing used refers to laws or certain rules.

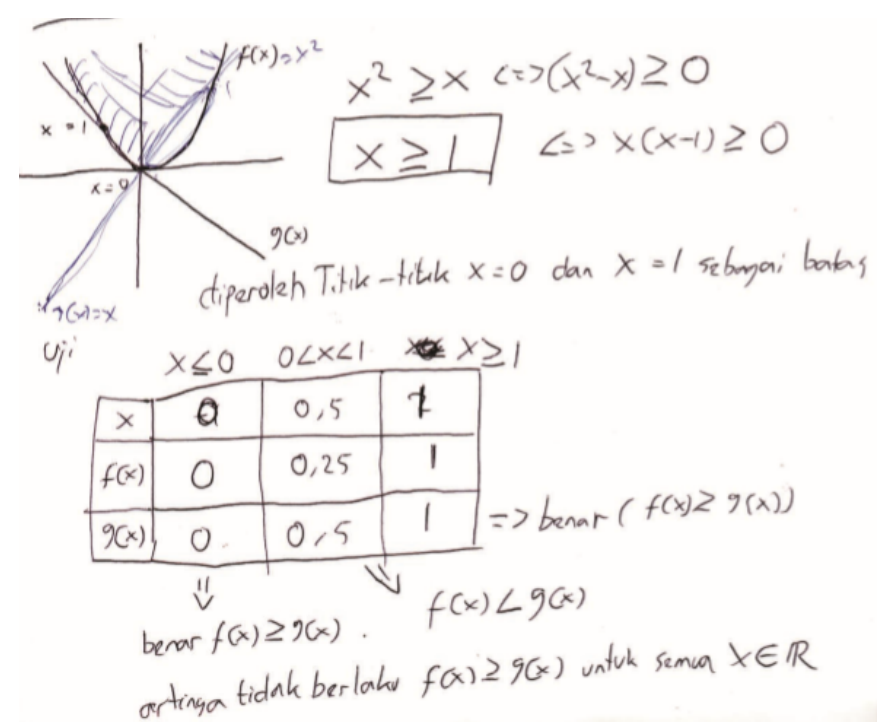

Figure 5a. A sample of S5's work

The subjects began proof by exploring the data (Mejía-Ramos \& Inglis, 2008), i.e., $x$ members of real numbers. In the exploration process, the subjects used the properties of real numbers (warrants) and classified them based on their prior knowledge. After that, they again paid attention to the formulas of the functions $f(x)$ and $g(x)$ (data) to investigate whether the statements $f(x) \geq g(x)$ for each real number was true or not. The following are the elaboration of the three types of backing and their relation to the other components of argumentation. 


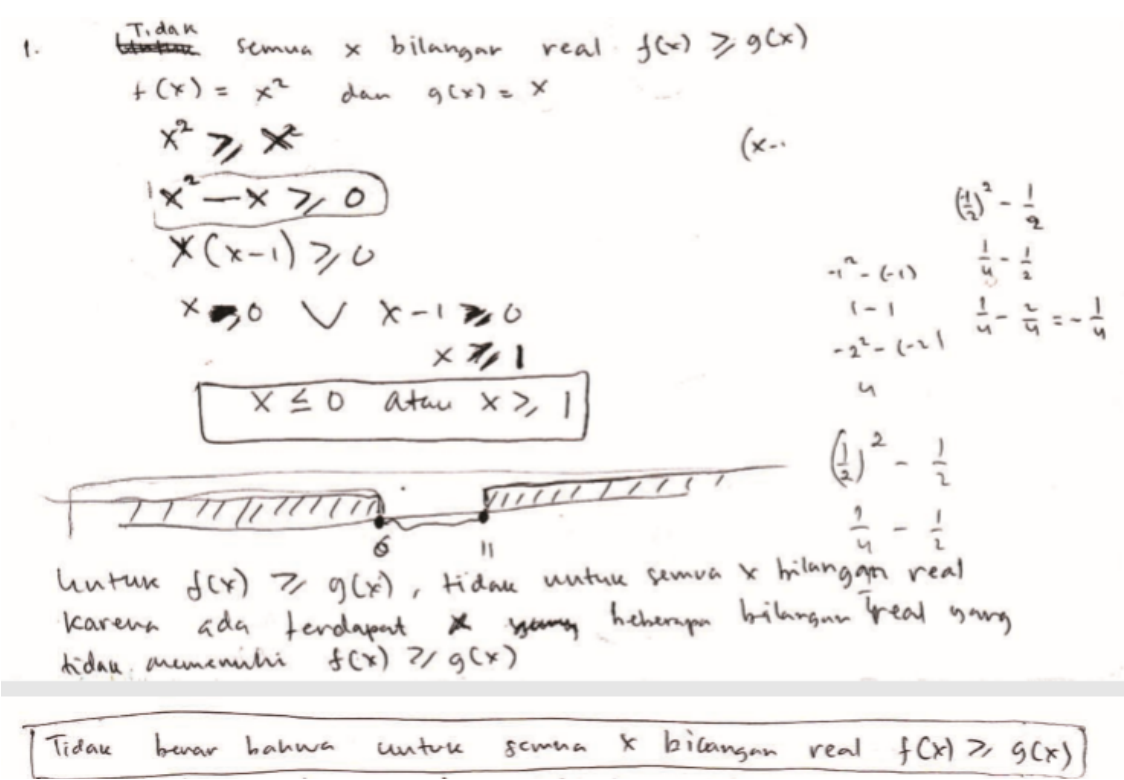

Figure 5b. A sample of S6's work

\section{Numerical Backing (Bn)}

Numerical backing is an additional reason used to strengthen warrant in the form of examples of numbers and calculations. Numerical backing occurs when S1 and S2 are unable to justify the truth of claims based on warrants only, so they need numerical examples and calculations to reinforce their reasoning. We investigated students' thinking processes to ensure the type of backing that is used.

The excerpt of the interview (EoI-1) shows that for $a<b$, S1 generated a claim $f(x)<$ $g(x)$ with the warrant of $-\mathrm{ab}<\frac{a^{2}}{b^{2}}$. The justification $\frac{a}{b}<\frac{a^{2}}{b^{2}}$ is based on a numerical backing (Bn) by assuming $a=1$ and $b=2$. After taking $a=1$ and $b=2$ and performing a mathematical calculation, $\frac{1}{2}>\frac{1}{4}$ is obtained, which is the basis for saying that $f(x)<g(x)$ for $a<b$. It is a strong reason to say that if $a<b$ then $\frac{a}{b}<\frac{a^{2}}{b^{2}}$ (Claim). Numerical backing occurs when S1 has difficulty determining the relation between $\frac{a}{b}$ and $\frac{a^{2}}{b^{2}}$. Figure 6 illustrates S1's argument based on the Toulmin scheme.

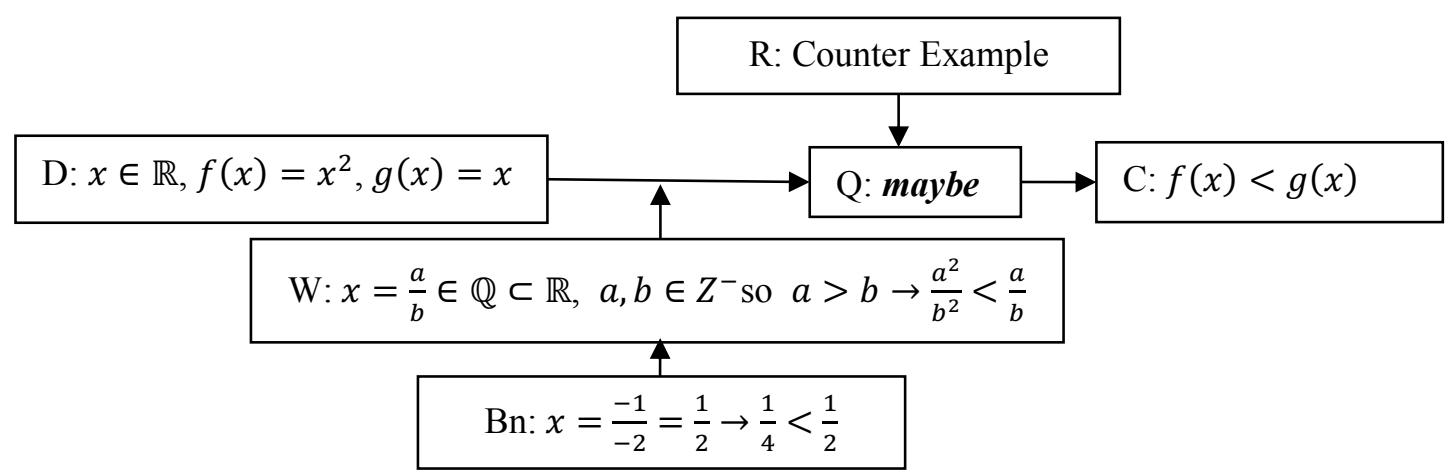

Figure 6. The argumentation structure of S1with a numerical backing on the first claim

A modal qualifier (maybe) used by S1 (Figure 6) indicates that he is not used to the numerical backing he is using as a counter-example (rebuttal), which means the statement is 
wrong. The subject also did not use the concept of proof with a counter-example for a mathematical statement that is disproved. The subject continued the proving process by constructing the second claim $\left(\mathrm{C}_{2}\right)$ and the third claim $\left(\mathrm{C}_{3}\right)$ for the relationship between the other $a$ and $b$. The complete argument of S1 is illustrated in Figure 7.

$\mathrm{S} 1$ constructed the three initial claims of the first claim $\left(\mathrm{C}_{1}\right)$, second claim $\left(\mathrm{C}_{2}\right)$ and third claim $\left(\mathrm{C}_{3}\right)$ before producing a final claim $(\mathrm{C})$. The three claims are based on four deductive warrants $\mathrm{W}_{1}, \mathrm{~W}_{2}, \mathrm{~W}_{3}$, and $\mathrm{W}_{4} . \mathrm{W}_{2}$ and $\mathrm{W}_{3}$ are supported by numerical backing (Bn1 and $\left.\mathrm{Bn} 2\right)$ which are selected based on grouping of $a$ and $b$. For $\mathrm{W}_{2}(a<b)$, examples selected are $\frac{1}{2}$ $(\mathrm{Bn} 1)$, whereas for $\mathrm{W}_{3}(a>b), \frac{3}{2}(\mathrm{Bn} 2)$ is chosen as an example. After reading the three claims along with the warrant and numerical backing that have been used, S1 validated the complete proof (Inglis \& Mejia-ramos, 2009) and claims that statements for all $x$ real numbers $f(x) \geq$ $g(x)$ are true except for $x=\frac{a}{b}, b \neq 0$ with $a<b$ (rebuttal). The claim was obtained by a numerical backing.

Numerical backing also occurs in S2 by taking $x=2$ for $x>0$ and $x=-1$ for $x<0$ and then squaring it (data). This produces the argumentation structure, as illustrated in Figure 8.

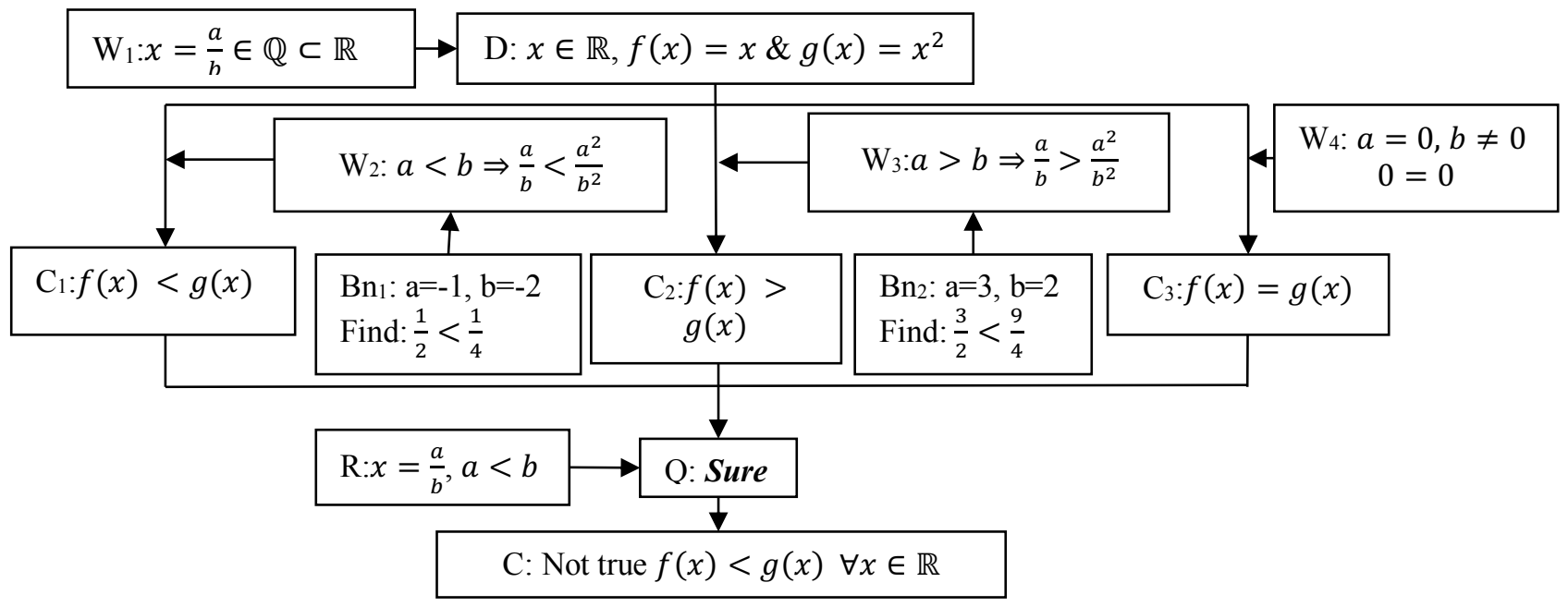

Figure 7. A complete argumentation structure of S1 with a numerical backing

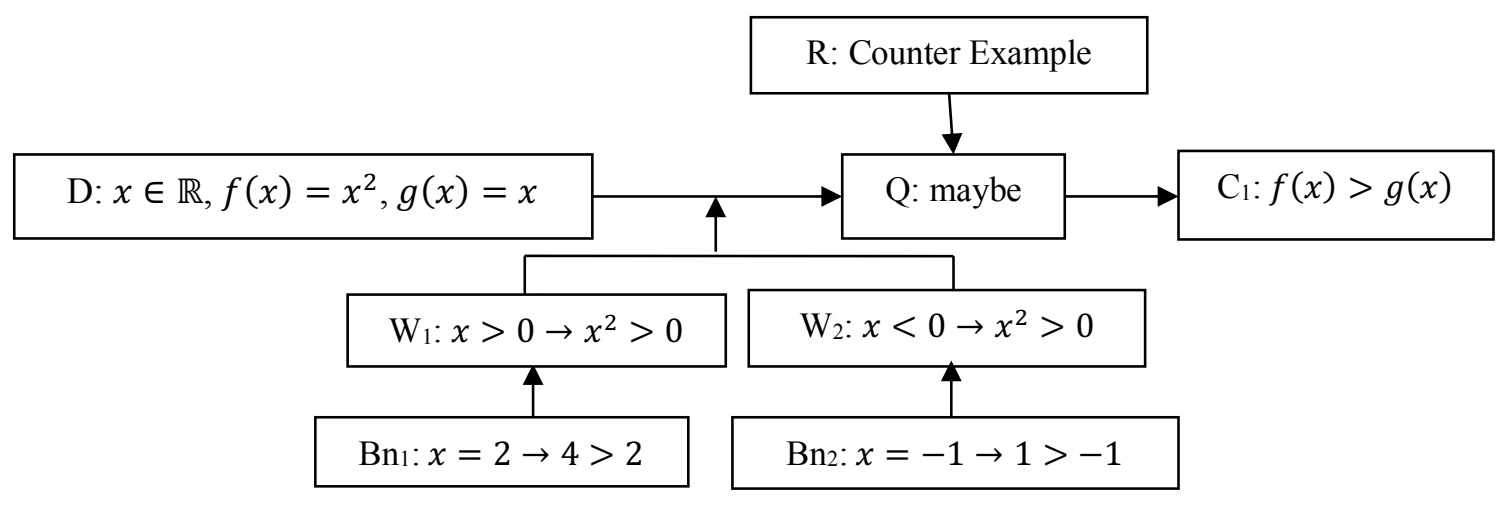

Figure 8. The argumentation structure of $\mathrm{S} 2$ with a numerical backing for the first claim 
The Toulmin argumentation scheme for the first claim is explained in Figure 8 with two warrants and two backings. S2 claimed that $f(x)>g(x)$ and justified the assertion given by the researcher, but the possible qualifier he used implies that he had doubts about the truth of the statement. A reworking process occurred, assuming the existence of a value of $x$ that causes a state of false value, resulting in an attempt to find clues to prove it (Mejía-Ramos \& Inglis, 2008), so that S2 constructed a second and third claim. To generate the second and third claim (final claim C), S2 also used the numerical backing to reinforce his warrant and found the counter-example to produce the correct claim, i.e. the statement that for all $x$ real numbers $f(x) \geq g(x)$ is true except for $x=\frac{1}{2}$ (rebuttal). This statement is based on numerical backing. The argumentation structure is illustrated in Figure 9.

Before arriving at the final claim, S2 made several claims. Mason, Burton, and Stacey (2010) label this initial claim as a conjecture. The numerical backing is used as a 'crucial experiment' (Balacheff, 1988) to convince oneself (Laamena, Nusantara, Irawan, \& Muksar, 2018 b) of the possibility of the truthfulness of statements. The subjects with numerical backing verified several cases by conducting an important experiment to show the truth of the conjecture. By generating generic examples, they convinced themselves about the produced claim. Based on some empirical evaluations (Figure 7, Figure 8), their doubts about the conjectures are reduced to subsequent proving processes (Inglis, Mejia-ramos, \& Simpson, 2007). From some of the produced claims, they then systematized as one of the main objectives of proof and argument that is to compose their work in a deductive system (de Villiers, 1990). One of the numerical backings used by the subjects is a rebuttal. It is a counter-example which assure the subjects to claim that if $x$ is a real number then it does not always apply $x^{2} \geq x$. It is the reason they do not try other real numbers.

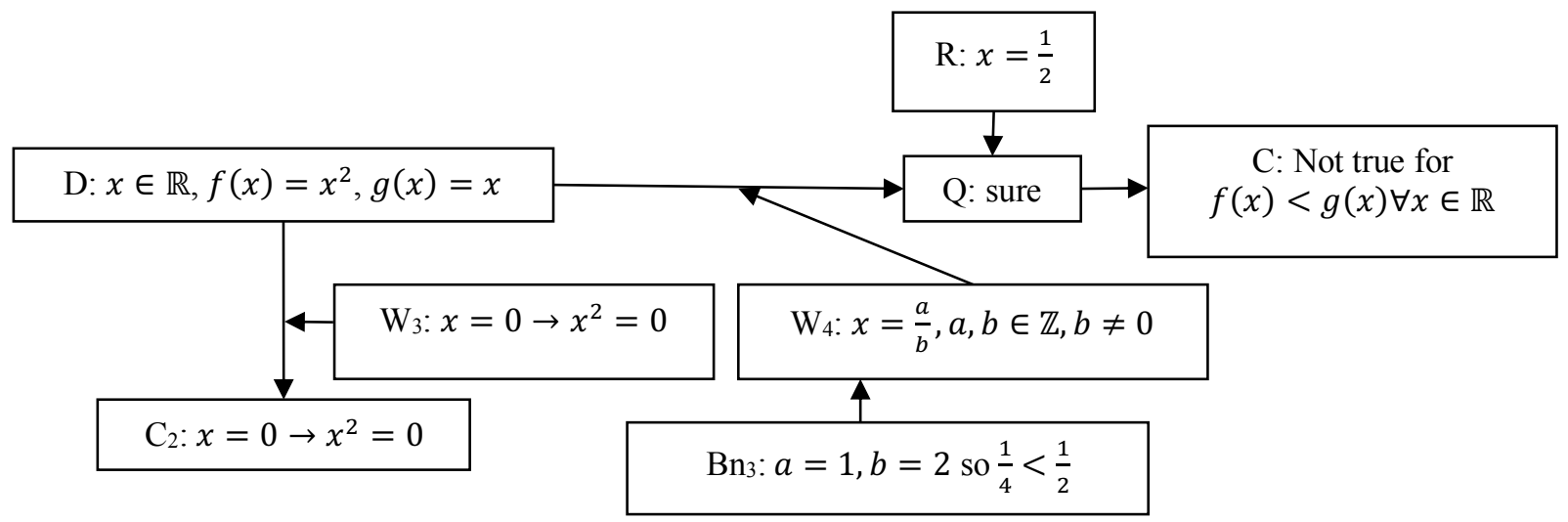

Figure 9. The argumentation structure of $\mathrm{S} 2$ with a numerical backing on the final claim

\section{Reference Backing $(\mathrm{Br})$}

Backing Reference $(\mathrm{Br})$ is an additional reason in the form of an explanation that refers to properties, theorem or definition used to support the warrant. Subjects, who used reference backing, did not use numerical examples or performed calculations but refer to the properties of integers. The following was an interview with one of the subjects using a reference backing.

\footnotetext{
S3: If $x$ is a positive integer then $x$ square is greater than $x$. So, if $x$ negative number then $x$ square must be greater than $x$.

$R$ : How did you get it?
} 
S3: The positive number when squared, it remains positive and certainly greater than the number itself and the negative number also if it is squared the result is positive and greater than the number itself

(The excerpt of interview 3, EoI-3)

S3 used a reference backing by referring to the properties of integers, i.e. the squares of positive and negative integers are always greater than the numbers themselves.

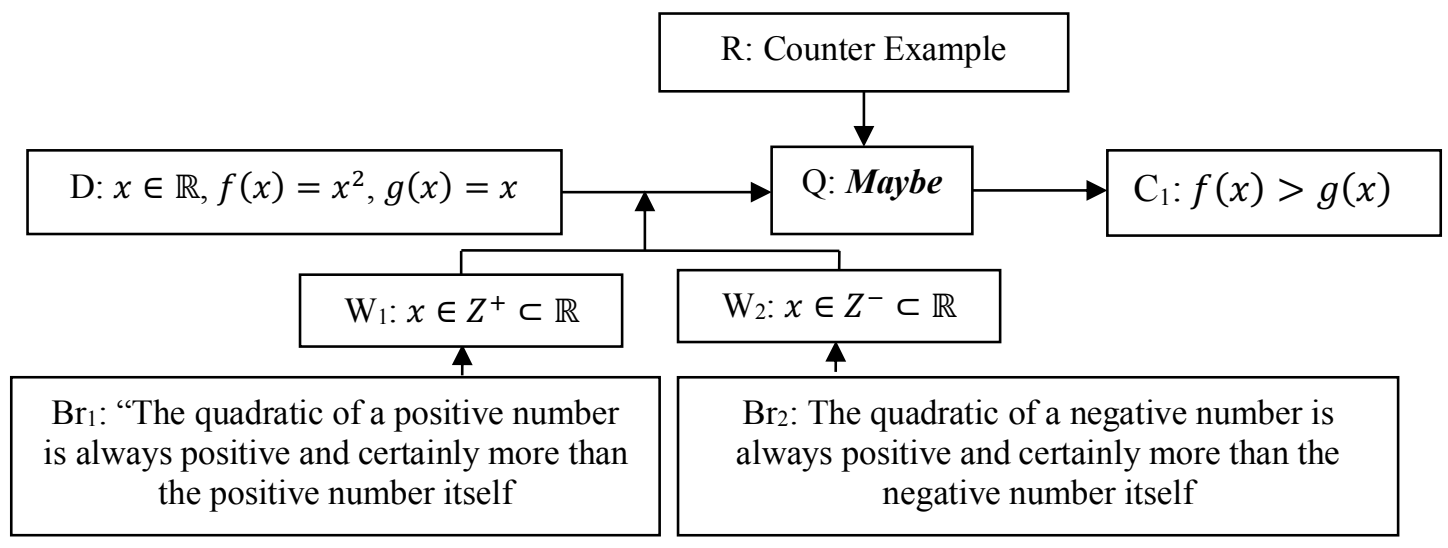

Figure 10. The argumentation structure of $\mathrm{S} 3$ with a reference backing on the first claim

Based on Figure 10, at this stage, S3 had not found the counter-example (rebuttal) and made the false claim. S3 realized that proving is not final, so he used the qualifier "maybe" for the claim. S3 continued the process of proving with numerical backing by defining the third category. Assuming $a=2, \mathrm{~S} 3$ generated a counter-example (rebuttal).

S4 also used a reference backing to support his deductive warrant. She claimed that $f(x) \geq$ $g(x)$ (claim) applies to all integers because the square of each integer is always greater or equal to the integer itself (warrant deductive). Then S4 took $x$ real numbers $\frac{1}{a}$ with a non-zero integer (warrant deductive), and obtained $\frac{1}{a^{2}}<\frac{1}{a}$ so that $f(x)<g(x)$. The following is an excerpt from a research interview with $\mathrm{S} 4$.

$R:$ Why did you say that $\frac{1}{a^{2}}<\frac{1}{a}$

$S 4$ : Because an integer is not zero, so if squared is always greater than a, it means $\frac{1}{a^{2}}<\frac{1}{a}$

$R:$ What is the relationship $a^{2}>a$ and $\frac{1}{a^{2}}<\frac{1}{a}$

S4: The numerator is the same, 1 . If $a^{2}>a$ then 1 divided by a large number, it will be less than 1 divided by a small number

(The excerpt of interview 4, EoI-4)

The reference backing used is the properties of integers and the axioms of the division. S4 found a counter-example (rebuttal) through reference backing and ensured that $f(x) \geq g(x)$ is not true for all real numbers because of $f(x)<g(x)$ for $\frac{1}{a}$ with $a$ non-zero integer. S4's argumentation is illustrated in Figure 11. 


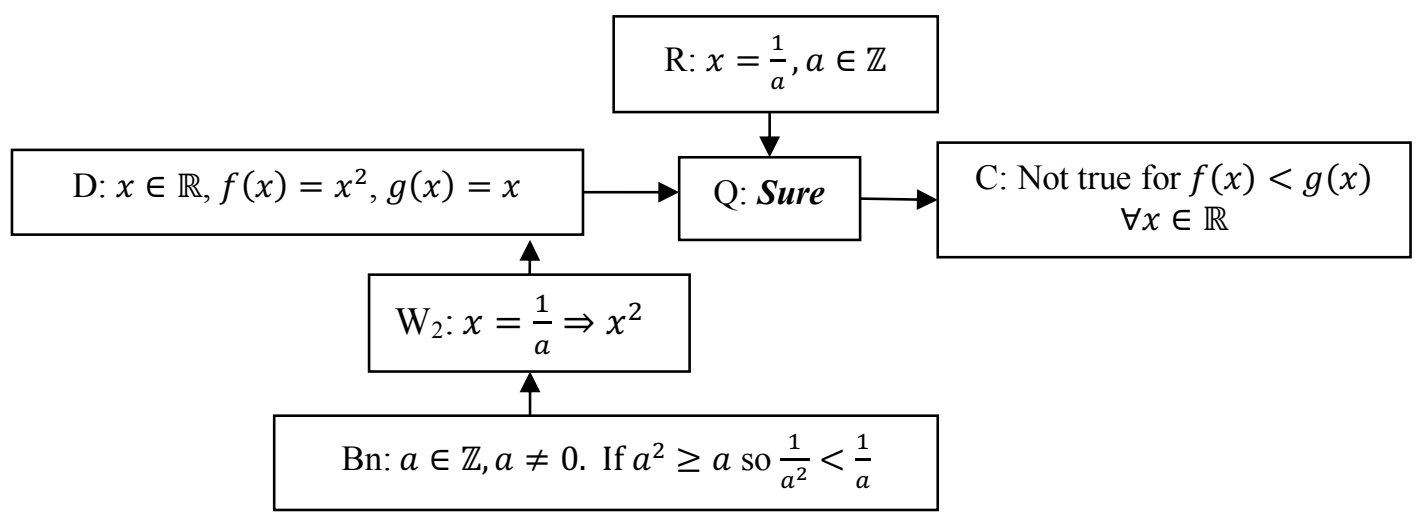

Figure 11. The argumentation structure of S4 with a reference backing on the final claim

Reference backing $(\mathrm{Br})$ is explicit in order to give an understanding of why the resulting claim is correct (de Villiers, 1990). The subjects who used reference backing make rational justification and try convincing the audience (Pedemonte, 2007). In formulating a reference backing, they tend to use verbal arguments (Edwards, 1999; Healy \& Hoyles, 2000). S3 identified the general aspect of the justification, but only for $x=\frac{1}{a}$, not all real numbers. According to Laamena, Nusantara, Irawan, and Muksar (2018a), the students who used definition or theorem are high-achieved students in mathematics. Healy and Hoyles (2000) assert that students prefer verbal proofs due to their explanatory power, yet at the same time, they expected to get low grades for such proof. Reference backing yields two rebuttals, i.e., $x=$ $\frac{1}{a}$ and $0<x<1$. S3 was very sure to claim that $0<x<1$ does not apply $x^{2} \geq x$ meanwhile $\mathrm{S} 4$ only found $x=\frac{1}{a}$ as a rebuttal. S4 still thought that "maybe" other counter-examples exist.

\section{Graphical Backing (Bg)}

Graphical backing is an additional reason in the form of graphs used to strengthen warrants. The subjects used the graphical backing to strengthen an inductive warrant or a deductive warrant. Graphical backing on an inductive warrant aims to convince itself (Laamena et al., 2018b). S5 used inductive warrant, i.e., examples of real numbers $1,2,-2,-4, \frac{1}{2}$ and $-\frac{1}{3}$ then claim that $f(x) \geq g(x)$ is not true for each real number. However, S5 had doubts about his claim and created a graph of the functions $f(x)=x^{2}$ and $g(x)=x$ on a Cartesian coordinate system. We investigated why students used graphical backing as follow.

$R$ : Why are you drawing the graph again?

S5: because of the question are real numbers,

$R:$ What is the relationship of graphs with real numbers?

S5: because the number I took does not include all the real numbers, but if I draw the graph it would include all real numbers

(The excerpt of interview 5, EoI-5)

S5's argumentation about using graphs concerns the graph as a representation of the real numbers and functions $f(x)=x^{2}$ and $g(x)=x$. Based on the graph, S5 found that the value for $g(x)=x$ is greater than $f(x)=x^{2}$ at the interval of 0 and 1 , so she assured (qualifier) that 
the assumption is correct. The graph is one of the functional representations that can help students to construct proof related to algebra (Rau, Aleven, \& Rummel, 2017). Visualizing a function (equation) as a graph makes the problem of complex real numbers more comprehensible. One of the argumentation structures with graphical backing by S5 is illustrated in Figure 12.

The graphical backing is also used by S6 to validate the statement of $x^{2} \geq x$ (solving the quadratic inequality). This process occurs when the subject made the false initial claim by stating that $f(x) \geq g(x)$ based on an intuitive structural warrant (Inglis et al., 2007). S6 commented that 'the square of a number is always greater than the number itself.' When we asked him about his claim, he replied the same reason 'the square of a number is always greater than the number itself.' The answer shows that S6 was very confident (qualifier) with the claim so as not to use the backing to strengthen warrant.

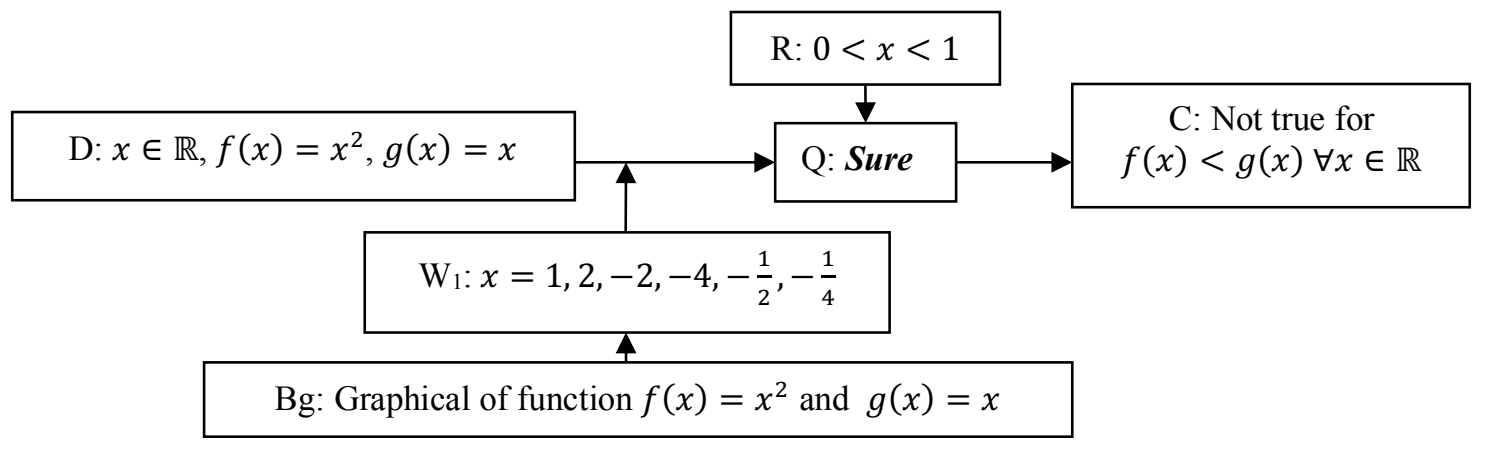

Figure 12. The argumentation structure of S5 with a graphical backing on the final claim

This false claim was not realized by S6. Then he was aware of proving the claim $x^{2} \geq x$. The claim $x^{2} \geq x$ became the second data $\left(\mathrm{D}_{2}\right)$. S6 proved the truth of $x^{2} \geq x$ by using a deductive warrant concerning the concept of fidelity. The use of the concept of fidelity is supported by a graphical backing in the form of a number line to determine the intervals of positive and negative value by using the test point. During the proving of $x^{2} \geq x$ the subject actually produced counter-examples (rebuttal) and yielded the claim that $f(x) \geq g(x)$ except for $0 \leq x \leq 1$, meaning that not all real numbers $x$ holds $f(x) \geq g(x)$. The argumentation of S6 can be seen in Figure 13.

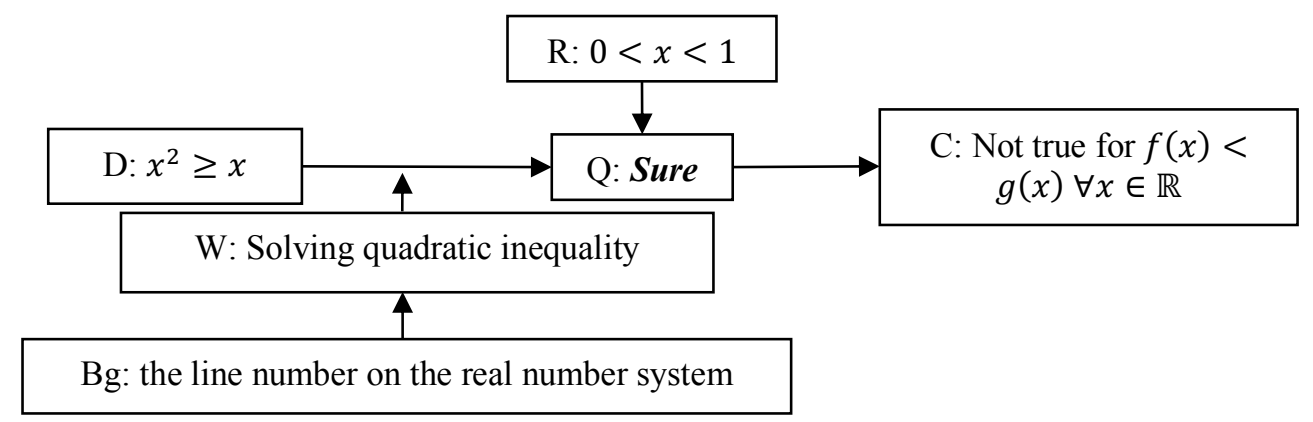

Figure 13. The argumentation structure of S6 with a graphical backing on the final claim

Graphical backing used by the subjects provides a complete rebuttal, i.e., $0<x<1$ with a qualifier "Sure" on the claim. A "Sure" on the claim relies on a correct mathematics procedure used in a proof. 
In proving, S6 did not only use a single backing but also multiple backings at once. The subject performed algebraic manipulations and factorization in quadratic equations (reference backing), used graphical backings and made use of numerical backing examples so that S6 was able to find a counter-example (rebuttal) and produced the correct claim. Thus, at the beginning of the thinking process, S6 produced wrong claims caused by weak intuitive structural warrants, but these errors can be corrected after using deductive warrants and supporting backings such as a reference backing, a graphical backing, and a numerical backing.

There are rebuttal differences generated by these three types of backing. Numerical backing produces two rebuttals, i.e., $x=\frac{1}{2}$ and $x=\frac{a}{b}$ for $a<b$. Reference backing produces rebuttal $x=\frac{1}{a}$ for $a$ whole number. Graphical backing produces rebuttal $0<x<1$. The wider rebuttal is $x=\frac{a}{b}$ for $a<b$ and $0<x<1$ for a whole number. However, in a wrong statement (disproved), pointing out one counter-example will be to be enough to prove the statement as wrong. Thus, the difference in rebuttal does not affect the viability of an argument that has been stated with any backing.

In the above three sections, we have described three types of backings (numerical backing, reference backing, and graphical backing), and analyzed their relationship to warrants and the examples used. We do not claim that these three types of backings are viable in all arguments. It depends on the given problem and the subjects solving it. The selection of problems from different fields of mathematics (e.g., geometry) allowed us to find different backing forms. The backing is important in determining the viability of a mathematical statement.

A numerical backing is always used to strengthen deductive warrants by taking numerical examples and then performing calculations to generate claims. Graphical backing and reference backing are used together with numerical backings to strengthen both inductive and indirect warrants. Graphical backing ensures the viability of the claim that has been generated by numerical backing and leads to find a complete rebuttal, i.e., $0<x<1$ not only $\frac{1}{2}$. Reference backing is more explanatory and used in conjunction with another backing.

Numerical backing and graphical backing are more explicit (as seen in subjects' work), whereas reference backing is more implicit in students' minds and serves as an explanation. The results show that students still feel uncertain (qualifiers) with their claims when they use reference backing, although the reference backing used is correct. Furthermore, the reference backing does not appear separately but together with numerical backing or graphical backing. The numerical backing seems to make students feel more confident (qualifier) with the claims they generate so that numerical backing can appear separately without the other forms of backings. Numerical backing help students to produce a different counter-example (rebuttal) but still yields a valid claim because the students simply provide an example of denial to indicate that the mathematical statement is false.

Simpson (2015) explicates that backing supports the warrant and it will be relevant if the warrant is challenged. Three roles of backing are proposed, i.e., (1) backing for the warrant's validity which relates to definition, (2) backing for the warrant's field which associates with a field on data, and (3) backing for the warrant's correctness which attempts to show that the warrant is correct. In the current research, the students' ways to provide backing for a warrant through samples of numbers, definition or theorem, and graphs. Numerical, reference, and graphical are backing which function as correcting the warrant. Reference backing which uses the property of number (positive, negative and null) relates to backing for the warrant's validity. 
Numerical backing links with backing for the warrant's field since the sample of numbers used based on the field of real numbers.

The word 'investigating' of the task given in this research is understood by the students as a hint to a trial error until they find the truth of the statement. In this process, students are more likely to use numerical backing by taking some special cases for $x$ real numbers. A numerical backing is used in the exploring and reworking stage. The students, who used the numerical backing, interpret the command word by making some trials of the real numbers. During a trial, the students construct some conjectures and generate multiple stream arguments. From the conjectures produced, students make systemization and final claims. Numerical backing and graphical backing are informal arguments but are needed in the process of constructing proofs to convince themselves as well as others and support reference backing.

The current research focused on a false mathematics statement. The students only need to provide a counter-example to prove it. In this case, the proof takes place shortly. We could not investigate a complex systemization in case the students apply various types of warrants and backings. If a correct statement is used, numerical and graphical backing cannot be used as a basis for proof, so the investigation of these three types of backing will be varied. Further research is encouraged to investigate backing on the basis of a correct mathematics statement so the complexity of the relationship between the backing and the other components of argumentation will be unraveled.

\section{Conclusion}

The research found that, in a mathematical proof, the students do not only employ definition or theorem (reference backing) but also the numbers (numerical backing) and graph (graphical backing) to easily make a claim. Numerical backing is backing in the form of samples of numbers and its calculation. Reference backing refers to the use of definition, theorem or properties of certain mathematics topics such as the properties of square numbers. Graphical backing is in the form of a graph of a function or number lines. Although the graph and the samples of numbers include in the inductive proof which cannot be used in a mathematical proof, graphical and numerical backing are the bridge to a deductive proof.

The backings are used to strengthen deductive and inductive warrant. A numerical backing reinforces the deductive warrant and function as single backing. A graphical backing supports the deductive warrant and is used with numerical backing. Reference backing fortifies the deductive and inductive warrant. It still requires numerical backing so not as a single backing.

A backing plays an essential role in (1) strengthening the warrant when the warrant is unable to justify the claim; (2) finding counter-examples (rebuttal); and (3) providing certainty (qualifier) for the claim. Numerical backing supports the students to find a counter-example as a rebuttal and assure the students (modal qualifier) on the claims. The students who used reference backing are 'not sure' (modal qualifier) on the claims, so they apply other backings and yield rebuttal. Graphical backing provides a 'quite sure' on the claims and a complete rebuttal. The roles indicate that backing directly determines claims, qualifiers, and rebuttal. The students utilize more than one backing depending on the qualifier toward the claim. The combination of three backings affirm the students on their claim. 
Laamena, C.M. \& Nusantoro, T.

\section{References}

Arzarello, F. (2007). The proof in the 20th century: From Hilbert to automatic theorem proving introduction. In P. Boero (Ed), Theorems in school (pp. 43-63). Netherlands: Brill Sense.

Arzarello, F., Paola, D., \& Sabena, C. (2009). Logical and semiotic levels in argumentation. In F.-L. Lin, F.-J. Hsieh, G. Hanna, \& M. de Villiers (Eds.), Proceedings of ICMI Study 19 conference: Proof and Proving in Mathematics Education (pp. 41-46). Taiwan: National Taiwan Normal University.

Balacheff, N. (1988). Aspects of proof in pupils practice of school mathematics. In D. Pimm (Ed.), Mathematics, Teachers and Children (pp. 216-235). London: Hodder \& Stoughton.

Bar-Tikva \& Judith. (2009). Old meta-discursive rules die hard. In F.-L. Lin, F.-J. Hsieh, G. Hanna, \& M. de Villiers (Eds.), Proceedings of the ICMI Study 19 conference: Proof and Proving in Mathematics Education (pp. 89-94). Taiwan: National Taiwan Normal University.

Boero, P., Garuti, R., \& Mariotti M, A. (1996). Some dynamic mental processes underlying producing and proving conjectures. In O. Figueras, J. L. Cortina, S. Alatorre, T. Rojano, \& A. Sepúlveda (Eds.), Proceedings of the 20th Conference of the International Group for the Psychology of Mathematics Education PME-XX (pp. 121-128). Valencia: Universitat de Valencia.

Bromley, D. B. T. (1986). The case-study method in psychology and related disciplines. Chichester: John Wiley \& Sons.

Burton, L. (2004). Mathematicians as enquirers: Learning about learning mathematics. Netherlands: Springer.

Chen, Y. T., \& Wang, J. H. (2016). Analyzing with Posner's conceptual change model and Toulmin's model of argumentative demonstration in senior high school students' mathematics learning. International Journal of Information and Education Technology., 6(6), 457-464. Doi: 10.7763/IJIET.2016.V6.732

de Villiers, M. (1990). The role and function of proof in mathematics. Pythagoras, 24, 17-24.

Edwards, L. D. (1999). Odd and even: Mathematical reasoning processes and informal proofs among high school students. Journal of Mathematical Behavior, 17, 498-504.

Feferman, S. (2000). Proof theory on the eve of the year 2000. Retrieved from http://wwwlogic.stanford.edu/proof.

Fraenkel, J. R., Wallen, N. E., \& Hyun, H. H. (2012). How to design and evaluate research in education (8th edition). New York: McGraw-Hill Companies, Inc.

Ginsburg, H. (1981). The clinical interview in psychological research on mathematical thinking: Aims, rationales, techniques. For the Learning of Mathematics, 1(1), 4-11.

Hanna, G., \& Villiers, M. (2012). Aspects of proof in mathematics education. In G. Hanna \& de Villiers. M. (Eds.), Proof and Proving in Mathematics Education: The 19th ICMI Study (pp. 1-10). Netherlands: Springer

Healy, L., \& Hoyles, C. (2000). A study of proof conceptions in algebra. Journal for Research in Mathematics Education, 31(4), 396-428.

Hitchcock, D., \& Verheij, B. (2006). Arguing on the Toulmin model: New essays in argument analysis and evaluation. Springer.

Inglis, M., \& Mejia-ramos, J. P. (2009). The effect of authority on the persuasiveness of mathematical arguments. Cognition and Instruction, 27(1), 25-50.

Inglis, M., Mejia-Ramos, J. P., \& Simpson, A. (2007). Modeling mathematical argumentation: The importance of qualification. Educational Studies in Mathematics, 66(1), 3-21. Doi: 10.1007/s10649006-9059-8

Knipping, C. (2008). A method for revealing structures of argumentations in classroom proving processes. ZDM-Mathematics Education, 2(40), 427-441.

Knipping, C. (2013). The social dimension of argumentation and proof in mathematics classrooms. In S. J. Cho (Ed.), Selected regular lectures from the 12th international congress on mathematical education (Vol 2. pp 215-228). Switzerland: Springer international publishing.

Krummheuer, G. (1995). The ethnography of argumentation. In P. Cobb \& H. Bauersfeld (Eds.), The emergence of mathematical meaning: Interaction in classroom cultures. (pp. 229-269). Hillsdal: Lawrence Erlbaum.

Laamena, C. M., Nusantara, T., Irawan, E. B., \& Muksar, M. (2018a). Analysis of the Students' argumentation based on the level of ability: Study on the process of mathematical proof. Journal of Physics: Conference Series, 1028(1). Doi: 10.1088/1742-6596/1028/1/012156 
Laamena, C. M., Nusantara, T., Irawan, E. B., \& Muksar, M. (2018b). How do the undergraduate students use an example in mathematical proof construction: A study based on argumentation and proving activity. International Electronic Journal of Mathematics Education, 13(3), 185-198. DOI: 10.12973/iejme/3836

Mason, J., Burton, L., \& Stacey, K. (2010). Thinking mathematically (2nd ed). Harlow: Pearson.

Mejía-Ramos, J. P., \& Inglis, M. (2008). What are the argumentative activities associated with proof? In M. Joubert (Ed.), Proceedings of the British Society for Research into Learning Mathematics (pp. 67-72).

Pedemonte, B. (2003). What kind of proof can be constructed following an abductive argumentation. Paper presented at The Third Conference on European Research in Mathematics Education. Retrieved from https://pdfs.semanticscholar.org/0abc/c73ab646e7a1e671aa568dd5c48f9aa53e61.pdf

Pedemonte, B. (2007). How can the relationship between argumentation and proof be analysed? Educational Studies in Mathematics, 66(1), 23-41.

Rau, M. A., Aleven, V., \& Rummel, N. (2017). Supporting students in making sense of connections and in becoming perceptually fluent in making connections among multiple graphical representations. Journal of Educational Psychology, 109(3), 355.

Selden, A., Selden, J., \& Benkhalti, A. (2018). Proof frameworks: A way to get started. PRIMUS, 28(1), 31-45.

Simpson, A. (2015). The anatomy of a mathematical proof: Implications for analyses with Toulmin's scheme. Educational Studies in Mathematics, 90(1). 1-17.

Solar, H., \& Deulofeu, J. (2016). Condotion to promote the development of argumentation compentence in the mathematics classroom. Bolema, 39(56), 1092-1112.

Stylianides, G. J., \& Stylianides, A. J. (2009). Ability to construct proof and evaluate one's own construction. In Proceeding ICMI 19th The Departement of Mathematics National Taiwan Normal University Taipei Taiwan (pp. 2-166). Taipei.

Stylianides, A. J. (2007). Proof and proving in school mathematics. Journal for Research in Mathematics Education, 38(3), 289-321.

Toulmin, S. E. (2003). The uses of argument. Cambridge: Cambridge University Press.

Tymoczko, T. (1986). New Direction in the Philosophy of Mathematics. Birkhauser Boston, Inc.

Ubuz, B., Dincer, S., \& Bulbul, A. (2012). Argumentation in undergraduate math courses: A study on proof generation. In T. Tso (Ed.), Proceedings of the 36th Conference of the International Group for the Psychology of Mathematics Education (Vol. 4, pp. 163-170). Taipei - Taiwan: PME

Ubuz, B., Dincer, S., \& Bülbül, A. (2013). Argumentation in undergraduate math courses: A study on definition construction. In A. M. Lindmeier \& A. Heinze (Eds.), Proceedings of the 37th Conference of the International Group for the Psychology of Mathematics Education (pp. 313-320). Kiel, Germany: PME. 